\title{
CRYPTIC CONSEQUENCES OF A DISPERSAL MUTUALISM: SEED BURIAL, ELAIOSOME REMOVAL, AND SEED-BANK DYNAMICS
}

\author{
Caroline E. Christian ${ }^{1}$ and Maureen L. Stanton \\ Center for Population Biology, University of California, Davis, California 95616 USA
}

\begin{abstract}
In moving seeds from one location to another, dispersers define the ecological context that a plant will experience throughout its lifetime. Because seed deposition sites may benefit one plant life cycle stage but not others, dispersal may give rise to a conflict between a plant's dispersal needs (e.g., predator escape) and its requirements for successful establishment (e.g., suitable habitat). In this study, we assessed the effects of two components of seed dispersal by ants (seed burial depth and elaiosome removal) at several stages during the recruitment of Leucospermum truncatulum, an ant-dispersed plant from the fynbos shrublands of South Africa. A seed-predator exclusion experiment revealed that the removal of elaiosomes significantly reduced rodent predation on seeds buried $1 \mathrm{~cm}$ deep and increased the viability of seeds that were not consumed. In contrast, we found that elaiosomes had no effect on the probability of a living seed emerging as a seedling. In a seed burial depth experiment in which predators were not excluded, deeper burial significantly enhanced seed survival, but this benefit came at the expense of reduced seedling emergence, delayed emergence, and smaller cotyledon size. Despite the potential importance of these seedling characteristics, elaiosomes and burial depth had no significant effect on seedling survival through the first year of this study. In contrast, burial depth had strong positive effects on the fraction of seeds that persisted in the seed bank. Although dormant individuals may die before germinating and reproducing, those that persist at greater soil depths can play a crucial role in rescuing populations from local extinction in unpredictable environments. Given the extreme variability in fire frequency in fynbos, the net effect of seed dispersal by ants on plant populations will depend on how temporal fluctuations in fire regimes influence cost-benefit thresholds related to seed dormancy and seed mortality.

Key words: ants; Argentine ants; fynbos; granivory; mutualism; Proteaceae; seed bank dynamics; seed dispersal; seed dormancy; seedling recruitment; South Africa.
\end{abstract}

\section{INTRODUCTION}

Seed dispersers influence the distribution and success of plants by defining the ecological context that an individual will experience throughout its lifetime. In transporting seeds to new environments, animal dispersers can influence plant performance by setting the stage for subsequent ecological interactions with competitors, predators, disease agents, and herbivores (e.g., Janzen 1970, Augspurger 1983, Kalisz et al. 1999). Although dispersal to new locations can benefit plants in numerous ways, it is less widely recognized that these services may also impose a variety of costs (e.g., Feldman et al. 1999). Understanding the net effect of dispersal, and thus its significance as an ecological and evolutionary force, will depend on the extent to which costs of dispersal outweigh the benefits.

Three factors are likely to influence the balance between costs and benefits resulting from seed dispersal by animals. First, the suitability of a site where a seed

Manuscript received 27 January 2003; revised 16 July 2003; accepted 21 July 2003; final version received 11 August 2003 Corresponding Editor: N. Cappuccino.

${ }^{1}$ Present address: Department of Ecology and Evolutionary Biology, University of California, Santa Cruz, California 95064 USA. E-mail: caroline@biology.ucsc.edu is deposited may be beneficial for one life cycle stage, but not for others (Howe 1990, Jordano and Herrera 1995, Schupp 1995). In such cases, studies of any single life stage may give a misleading picture of the overall fitness consequences of dispersal (Hanzawa et al. 1988, Horvitz and Schemske 1995). Second, individual seeds vary in how far they are dispersed and how deeply they are buried in the soil; the pattern and magnitude of this variation may determine whether dispersal imposes a net cost or benefit (Pudlo et al. 1980, Anderson 1988). This caveat applies to mutualisms more broadly, in that changes in the amount of reward consumed or the degree of services provided can reduce or reverse the fitness consequences of the interaction (e.g., Bronstein 1994). Third, spatial and temporal variation in the ecological setting that dispersed seeds experience may also determine costs and benefits of animal dispersal. For example, variation in the abundance of mutualists, predators, and abiotic conditions has been shown to govern cost-benefit thresholds in some mutualisms (e.g., Cushman and Whitham 1989, Horvitz and Schemske 1990).

Seed dispersal by ants has the potential to influence several important demographic attributes of plant populations (Addicott 1986, Hanzawa et al. 1988). The seeds of ant-dispersed plants have highly attractive, oil- 
rich coverings or appendages, known as elaiosomes (Van der Pijl 1972). When such seeds fall to the ground, some ant species rapidly move them to nest chambers below ground, where they consume the elaiosomes, and in many cases, discard the bare seeds unharmed. In the process of dispersal, ants may influence the proximity of a seed to its maternal parent (Bond and Stock 1989), the local densities of intra- and interspecific neighbors (Kalisz et al. 1999), the depth at which seeds are buried (Auld 1986, Musil 1991), and the presence or absence of the elaiosome (Hughes and Westoby 1992). In this paper, we focus specifically on the demographic consequences of seed burial and elaiosome removal. The effects of dispersal distance and local seed density have been addressed elsewhere (Christian 2002).

By burying seeds and removing elaiosomes, ants may influence seed and seedling fates in both positive and negative ways. First, they may enhance seed survival by protecting individuals from vertebrate seed predators (Heithaus 1981, Bond and Breytenbach 1985). Seeds buried more deeply may have a greater chance of evading rodent predators (e.g., Reichman 1980, Fuchs et al. 2000). Moreover, because rodents also use elaiosomes as cues for locating seeds, elaiosome removal can reduce seed predation levels on the soil surface (Slingsby and Bond 1985) and below ground (Heithaus 1981). In contrast, seeds buried below some critical depth may fail to emerge (Wesson and Wareing 1967, Guo et al. 2001), emerge later in the season (Black 1956), or have fewer reserves remaining after emergence (Seiwa et al. 2002).

Determining the consequences of seed dispersal by ants for plant populations has become increasingly important due to the global expansion of several highly invasive ant species. In their introduced ranges, exotic ants are decimating native arthropod faunas, especially native seed-dispersing ants (reviewed in Holway et al. 2002). Although exotic ants could in theory substitute for the dispersal services provided by native taxa, in many cases they are inferior dispersers, or fail to disperse seeds at all (Christian 2001, Zettler et al. 2001, Carney et al. 2003). One of the most striking examples comes from South Africa, where the Argentine ant displaces many native ant dispersers and does not disperse seeds (Bond and Slingsby 1984, Christian 2001). Understanding how the disruption of such mutualisms will impact native plant populations first requires knowledge of how native ants influence key plant demographic rates.

In this study, we document the consequences of seed burial and elaiosome removal at multiple stages in the recruitment pathway for an ant-dispersed shrub from South Africa, Leucospermum truncatulum. In contrast to most previous field studies, where seeds were planted directly in the soil and could not be retrieved to determine survival rates of ungerminated seeds, we used seed-cage experiments that allowed us to track the fates of all planted seeds (sensu Kalisz 1991). By combining field experiments that mimic components of ant dispersal with comparative studies in natural populations, we addressed the following questions: (1) What is the range of natural variation in seed burial depth in Leucospermum? (2) How does elaiosome removal affect seed predation by vertebrates after seeds are buried? (3) What are the joint effects of seed burial depth and elaiosome removal on survivorship, persistence, emergence, and growth during the seed and seedling life cycle stages? (4) Is there an optimal seed burial depth that maximizes seed and seedling success? (5) How might seedling recruitment dynamics be affected in areas invaded by Argentine ants?

\section{Study System}

Our research was conducted in the Kogelberg Biosphere Reserve, located in the fynbos shrublands of the southwestern Cape Province, South Africa ( $34^{\circ} 20^{\prime} \mathrm{S}$, $\left.18^{\circ} 58^{\prime} \mathrm{E}\right)$. Fynbos is a fire-prone vegetation type dominated by diverse evergreen shrubs and perennial graminoids restricted to low-nutrient soils (Cowling 1992). This area experiences a Mediterranean-type climate, with warm, dry summers (October-March) and cool, wet winters (June-August). Winter rains and summer fog account for the annual precipitation of $\sim 750$ $\mathrm{mm}$. Soils at the site are uniform, deep, and sandy and are derived from the light-colored quartzitic sandstones of the Table Mountain Sandstone Group, the dominant geologic formation in fynbos. The site occurs in the Palmiet River Valley at 120 m elevation, is $\sim 3$ ha in size, and is representative of the surrounding fynbos. Vegetation at the site is dominated by several species in the Proteaceae, including Leucospermum truncatulum, Leucodendron xanthoconus, Aulax umbellata, and Protea longifolia, as well as several Erica species (see Boucher 1978 for detailed vegetation description). Interspersed among these shrubs is a mixture of Restionaceae. Fire is a highly variable component of fynbos systems and can occur unpredictably every 2 to 40 years during the summer or autumn months (December-May). The site was last burned $\sim 30$ years ago and has received a uniform management history.

Leucospermum truncatulum (Proteaceae) is an antdispersed shrub that is endemic to the southwestern Cape region. As with most fynbos shrub species, Leucospermum is killed by fire, lacks the ability to resprout, and thus relies entirely on dormant seeds for population regeneration. Adult plants are either killed during fires, or senesce within 8-12 years in the absence of fire. Following a burn, bursts of germination give rise to even-aged stands, with little recruitment occurring until the next burn. Seedling emergence begins with the winter rains following a fire, and continues through August. Plants begin reproducing in their third or fourth year. This species bears few, large seeds (49.16 mg \pm 0.46 [mean $\pm 1 \mathrm{sE}$ ], $N=60$ seeds) that are completely encased by an elaiosome. Seeds ripen and fall singly to the ground during summer months 
(November-March) when ants are most active. If ants do not rapidly bury fallen seeds, predation rates by rodents are nearly $100 \%$ (Christian 2001). The length of time between consecutive fires, in concert with dispersal by ants, determines the extent to which plants regenerate from seed-bank reserves (Pierce and Cowling 1991, Christian 2001).

Although many ant species are attracted to the large seeds of Leucospermum truncatulum, three ant species are responsible for most dispersal: Anoplolepis custodiens, A. steingroveri, and Pheidole capensis (Christian 2001, 2002). For large-seeded plants such as Leucospermum, ants are exclusively seed dispersers and do not consume seeds. Seed enemies include rodent predators, such as the Cape spiny mouse (Acomys subspinosus) and the striped mouse (Rhabdomys pumilio), invertebrates, and the roots of the hemiparasitic plant Mastersiella digitata (Restionaceae), which attach their roots to dormant seeds and other living organic matter in the soil (C. Christian, personal observation). Caching of ant-dispersed Proteaceae by rodents has not been reported for this system (Midgley et al. 2002).

\section{Methods}

\section{Natural variation in seedling emergence depth}

To estimate the range of seedling emergence depths in naturally occurring populations, we excavated and measured the hypocotyl lengths of 92 randomly selected Leucospermum seedlings in a 1-ha area three months after a prescribed burn (August 2000). In the ant-dispersed Proteaceae, the length of the hypocotyl provides a good measure of germination depth because of the presence of a distinctive foot-like structure at the intersection of the hypocotyl and the radicle (Auld 1986, Bond and Stock 1989). Thus, this measure provides an estimate of the distribution of emergence depths, but does not necessarily reflect the complete distribution of seed depths. To infer emergence depth, we measured the region of the hypocotyl between the "foot" and the soil surface. To assess the relationship between hypocotyl length and seedling performance, we also measured the maximum cotyledon length and width and seedling height for each excavated seedling.

\section{Elaiosomes and post-burial predation by vertebrates}

To assess the joint effects of elaiosomes and vertebrate predation on buried seeds, we conducted a factorial experiment in which we manipulated elaiosomes and vertebrate access to seed banks created in the field. We arranged experimental seed banks in 10 blocks, each of which was $5 \times 10 \mathrm{~m}$ in size, scattered throughout a 1-ha area in fynbos that had been unburned for over 30 years and where only a few senescent Leucospermum plants remained. In each block, we randomly assigned four positions to one of four treatment combinations: (1) elaiosomes removed and vertebrate predators excluded, (2) elaiosomes removed and ver- tebrate predators allowed access, (3) elaiosomes present and vertebrate predators excluded, and (4) elaiosomes present and vertebrate predators allowed access to seeds (10 blocks $\times 4$ treatment levels $=40$ experimental seed banks). Elaiosomes were either removed manually from seeds by squeezing mature seeds out from the elaiosome casing (-elaiosome treatment) or were partially removed by gently peeling off approximately one-eighth of the eliaosome to control for handling of seeds (+elaiosome treatment). Prior to handling seeds, we rinsed our hands in water to further minimize experimental artifacts and unintentional olfactory cues. To exclude small vertebrates from seeds, we fastened squares of $1-\mathrm{cm}^{2}$ hardware cloth mesh over experimental seed banks. Seeds for the experiment were collected in nearby fynbos $(\sim 30-50 \mathrm{~m}$ away) during peak fruiting season in January-February 2000. All seeds were inspected to include only hard, filled seeds, and then were combined to form a bulk sample. Seeds were stored in a cool, dry place until the end of the fruiting season (March 2000), when they were planted into experimental seed banks (6-10 March 2000). A subsequent check of the experimental seed banks in late March 2000 revealed that digging by rodents had not occurred immediately following the implementation of the experiment. To minimize disturbance of rodent activity during the experiment, we did not revisit the site until 15 May 2000, when the plots were burned, and then again in mid-June 2000, when we began censusing seedling emergence.

Prior to planting seeds in experimental seed banks, we sieved the soil in a $15 \times 15-\mathrm{cm}$ area and to depth of $15 \mathrm{~cm}$ using a $1.5-\mathrm{mm}^{2}$ mesh screen; this removed Leucospermum seeds while allowing seeds of most other species to remain in the seed bank. After removing naturally occurring Leucospermum seeds, we then placed open-topped baskets made of aluminum window screen $\left(10 \times 10 \times 13 \mathrm{~cm}, 1-\mathrm{mm}^{2}\right.$ mesh size $)$ into the pits and filled them with the sieved soil. Because the soil at the study sites is light and sandy, sieved soil did not differ greatly in soil structure or compaction relative to unsieved soil (C. E. Christian, personal observation). Each basket was buried $12 \mathrm{~cm}$ deep with 1 $\mathrm{cm}$ of the rim emerging above the surface to facilitate relocation. In each basket, we planted 16 experimental seeds $1 \mathrm{~cm}$ deep and $2 \mathrm{~cm}$ apart. This density corresponds to levels observed in natural populations (see Christian 2002). After planting seeds, the site was burned during the natural fire season in a prescribed fire on 15 May 2000. For one year following the burn, we monitored seedling emergence from each seed bank.

To determine the fates of seeds that did not emerge as seedlings, we sieved soil from the experimental seed banks to recover any remaining seeds in April 2001. All recovered seeds were tested for viability. Because of their large size, we dissected seeds to visually determine whether they contained live, plump embryos (vs. withered and dried embryos). Because seed baskets 
allowed us to account for all planted seeds, we scored any unrecovered seeds as dead, presumably due to a combination of predation, fire, and seed decomposition.

\section{Elaiosomes and seed burial depth}

In March 2000, we conducted a second seed-basket experiment in an adjacent 1-ha area to evaluate the joint effects of seed burial depth and elaiosome removal on seeds exposed to natural levels of predation. To mimic seed burial by ants, we planted 16 seeds in aluminum mesh baskets at one of four depths $(1,3,6$, and $12 \mathrm{~cm})$ spanning the range of observed emergence depths based on hypocotyl length data. All seeds in a cage were planted at the same depth. For half of the cages in each depth treatment, we removed elaiosomes from seeds (-elaiosomes); for the other half we partially removed elaiosomes to control for handling (+elaiosomes). We randomly assigned one replicate of each depth and elaiosome treatment combination to positions within 10 blocks across the study site (10 blocks $\times 8$ treatment levels $=80$ cages $)$. As before, all seeds were collected from a nearby site during peak fruiting season (February-March 2000), and combined in a bulk sample. As in the seed-predation experiment, we planted seeds after peak fruiting season (March) then burned plots in the autumn (15 May 2000) to stimulate seed germination.

After the prescribed burn, we scored the following response variables once every two weeks (starting 15 June 2000): week of seedling emergence, cotyledon area (measured as an ellipse using maximum cotyledon length and width) with first two true leaves present $\left(\mathrm{mm}^{2}\right)$, seedling height $(\mathrm{mm})$, and seedling survival until April 2001. At this time, we excavated all seed baskets, sieved the soil, and determined the fates of ungerminated seeds as described in the seed-predation experiment.

In the second seed-basket experiment only, we recorded the causes of seed and seedling mortality based on visual inspection and estimated per-cage survival. We assigned all dead seeds to one of three seed-fate categories: (1) seeds with inviable (i.e., withered) embryos, (2) dead seeds covered by the parasitic roots of Mastersiella digitata, and (3) seeds that were not recovered from seed cages, presumably due to a combination of seed predation, fire, unsuccessful emergence, seed decomposition, and experimental error. We inferred that seedlings that were heavily bitten or chewed died as a result of vertebrate herbivores, such as grysbok (Raphicerus melanoti) and grey rhebok ( $P e$ lea capriolus), or invertebrate herbivores, including Curculionidae (Eremnus sp., Rhinocus sp., and Phylictinus sp.) and polyphagous Lepidoptera. We assumed that seedlings pulled out of the ground were killed by baboons (Papio ursinus), whereas wilted seedlings died as a result of desiccation, rotting, or other causes.

\section{Statistical analyses}

In the seed-predation experiment, we assessed variation in seed survival among treatment levels using a three-way analysis of variance (ANOVA) with block, seed-predator exclusion $(+/-)$, and elaiosome removal $(+/-)$ treatments as grouping factors. Proportions were arcsine square-root transformed for the analysis. Pairwise comparisons among the four treatment levels were conducted using the Tukey-Kramer method (GLM procedure; SAS Institute 1998).

In the seed burial experiment, we assessed the consequences of seed burial and elaiosome removal for each step in the recruitment pathway using three-way ANOVAs with block, burial depth, and elaiosome removal as grouping factors and with either the probability of seed survival, seedling emergence, or seedling survival as the response variable. We calculated the probability of seed survival as [(initial number of seeds/cage) - (number of inviable seeds/cage) (number of unrecovered seeds/cage) $] \div$ (initial number of seeds/cage). Because seedling emergence and seedling survival are dependent on survival to these stages, we calculated these vital rates as conditional probabilities. We defined the conditional probability of seedling emergence|seed survival (hereafter seedling emergence) as (number of emerged seedlings/cage) $\div$ [(initial number of seeds/cage) - (number of inviable seeds/ cage) - (number of unrecovered seeds per cage)]. Similarly, we defined the conditional probability of seed dormancy|seed survival (hereafter seed dormancy) as the probability that a live seed persisted as a seed given that it survived (i.e., 1 - the probability of seedling emergence). We calculated the conditional probability of seedling survival|seedling emergence (hereafter seedling survival) as (number of seedlings surviving through the first year/cage) $\div$ (number of emerged seedlings/cage). All probabilities were arcsine square-root transformed for statistical analyses. Due to baboon damage to a seed cage from one block, we used Type III sums of squares (GLM Procedure; SAS Institute 1998). Because of the multiple analyses, we used a Bonferroni adjustment for significance tests $(\alpha=$ $0.05 / 3$ or 0.0167$)$.

In a second analysis, we used multivariate analysis of variance (MANOVA) to test for the effects of the experimental grouping factors, including block, seed burial depth, and elaiosome manipulation, on three measures of performance during the transition from seedling emergence to seedling survival: seedling emergence timing, cotyledon area, and final seedling height. We used Bonferroni-adjusted univariate ANOVAs on each response variable to further assess which variables were responsible for significant terms in the MANOVA model. All analyses were based on mean values per seed cage.

To assess the net effects of burial depth and elaiosomes on expected population success (seeds and seed- 


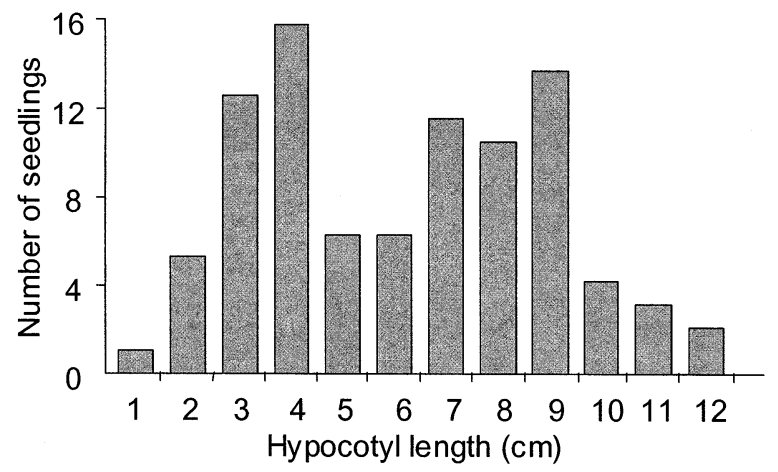

FIG. 1. Frequency distribution of hypocotyl lengths for Leucospermum truncatulum seedlings excavated from a natural population.

lings combined) one year after an experimental burn, we used a two-factor ANOVA to assess the effect of elaiosomes and burial depth on the probability of a individual surviving as either a viable, ungerminated seed or as a seedling until the end of the first year of the experiment. We calculated this total survival probability as [(number of viable, ungerminated seeds after one year) + (number of live seedlings after one year)] $\div$ (initial number of seeds/basket). All probabilities were arcsine square-root transformed, and Type III sums of squares were used for analyses.

\section{RESUlts}

\section{Natural variation in seedling emergence depth}

In natural Leucospermum populations, we found that the hypocotyl length of excavated seedlings was highly variable, ranging from 1 to $12 \mathrm{~cm}$ and averaging 5.79 $\pm 0.29 \mathrm{~cm}$ (mean $\pm 1 \mathrm{se}, N=92$ seedlings; Fig. 1$)$. The distribution of hypocotyl lengths was bimodal, as indicated by a significantly negative kurtosis parameter $(\gamma=-0.99, Z=1.82, P=0.034$, two-tailed test; Zar 1996). Regression analyses revealed that cotyledon area and seedling height were negatively associated with hypocotyl length (cotyledon area, $F_{1,85}=14.68$, $P=0.0002, y=0.09-0.002 x, R^{2}=0.147, N=87$; seedling height, $F_{1,83}=10.40, P=0.0018, y=65.93$ $\left.-0.17 x, R^{2}=0.111, N=87\right)$.

\section{Elaiosomes and post-burial predation by vertebrates}

In the elaiosome-removal and vertebrate-exclusion experiment, we found that both elaiosomes and predators significantly decreased survival rates of buried seeds (predators, $F_{1,27}=5.36, P=0.029$; elaiosomes, $\left.F_{1,27}=10.95, P=0003\right)$. In addition, there was a significant predator $\times$ elaiosome interaction term, indicating that the negative effects of elaiosomes were significantly greater in the presence of vertebrate predators $\left(F_{1,27}=4.55, P=0.042\right.$; Fig. 2$)$. In the presence of predators, survival of seeds with elaiosomes was reduced $67 \%$ relative to those without elaiosomes (Fig. 2). In protected cages, survival was reduced by $11 \%$

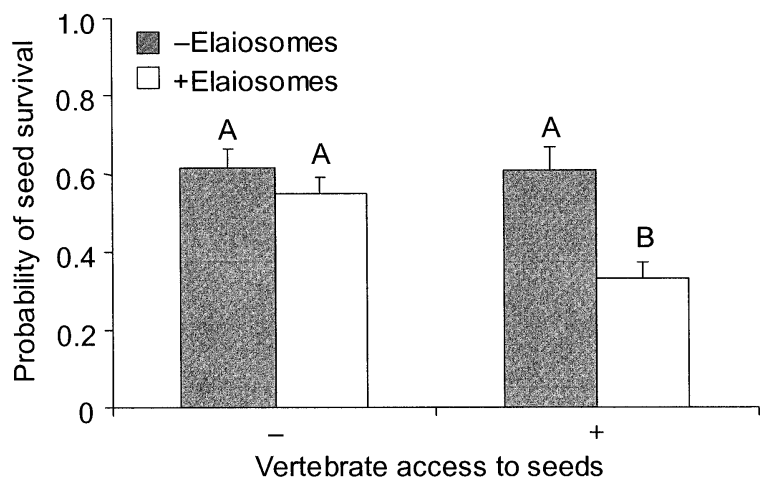

FIg. 2. Survival (means $+1 \mathrm{SE}$ ) of buried Leucospermum truncatulum seeds with and without elaiosomes in the presence or absence of vertebrate seed predators. Letters above bars correspond to results from pairwise comparison tests (Tukey-Kramer hsd).

for seeds with elaiosomes, indicating that elaiosomes have a negative effect on seeds even in the absence of predators.

\section{Elaiosomes and seed burial depth}

Survival and emergence.-For seeds exposed to natural levels of predation, elaiosomes reduced seed survival by an average of $38 \%$ (Table 1a, Fig. 3a). In contrast, increased burial depth had a significantly positive effect on seed survival (Table 1a, Fig. 3a). There was no significant interaction between burial depth and

TABLE 1. Consequences of seed burial depth and elaiosomes for early stages of Leucospermum recruitment: (a) seed survival after one year; (b) probability of emergence for surviving seeds; and (c) probability of survival for emerged seedlings.

\begin{tabular}{lrrrc}
\hline \hline \multicolumn{1}{c}{ Source } & df & \multicolumn{1}{c}{ MS } & \multicolumn{1}{c}{$F$} & $P$ \\
\hline a) Seed survival & & & & \\
$\quad$ Block & 9 & 127.81 & 1.40 & 0.206 \\
Elaiosome (E) & 1 & 2185.55 & 23.99 & $<0.0001$ \\
Depth (D) & 3 & 310.15 & 3.41 & 0.023 \\
E $\times$ D & 3 & 97.78 & 1.07 & 0.367 \\
Error & 62 & 91.08 & & \\
$\quad R^{2}=0.45$ & & & &
\end{tabular}

b) Probability of emergence for surviving seeds

$\begin{array}{lrrrc}\text { Block } & 9 & 198.63 & 0.74 & 0.671 \\ \text { Elaiosome (E) } & 1 & 1.19 & 0.00 & 0.947 \\ \text { Depth (D) } & 3 & 14226.67 & 53.00 & <0.0001 \\ \text { E } \times \text { D } & 3 & 25.10 & 0.09 & 0.963 \\ \text { Error } & 62 & 268.43 & & \\ \quad R^{2}=0.73 & & & & \end{array}$

c) Probability of survival for emerged seedlings

$\begin{array}{lrrrr}\text { Block } & 9 & 1553.32 & 1.69 & 0.124 \\ \text { Elaiosome (E) } & 1 & 1394.49 & 1.51 & 0.226 \\ \text { Depth (D) } & 2 & 896.57 & 0.97 & 0.415 \\ \text { E } \times \text { D } & 2 & 773.79 & 0.84 & 0.439 \\ \text { Error } & 41 & 921.49 & & \end{array}$

$$
R^{2}=0.38
$$

Notes: See Methods for probability calculations. "Elaiosome" refers to the presence or absence elaiosomes, and "depth" refers to the depth at which experimental seeds were buried. 

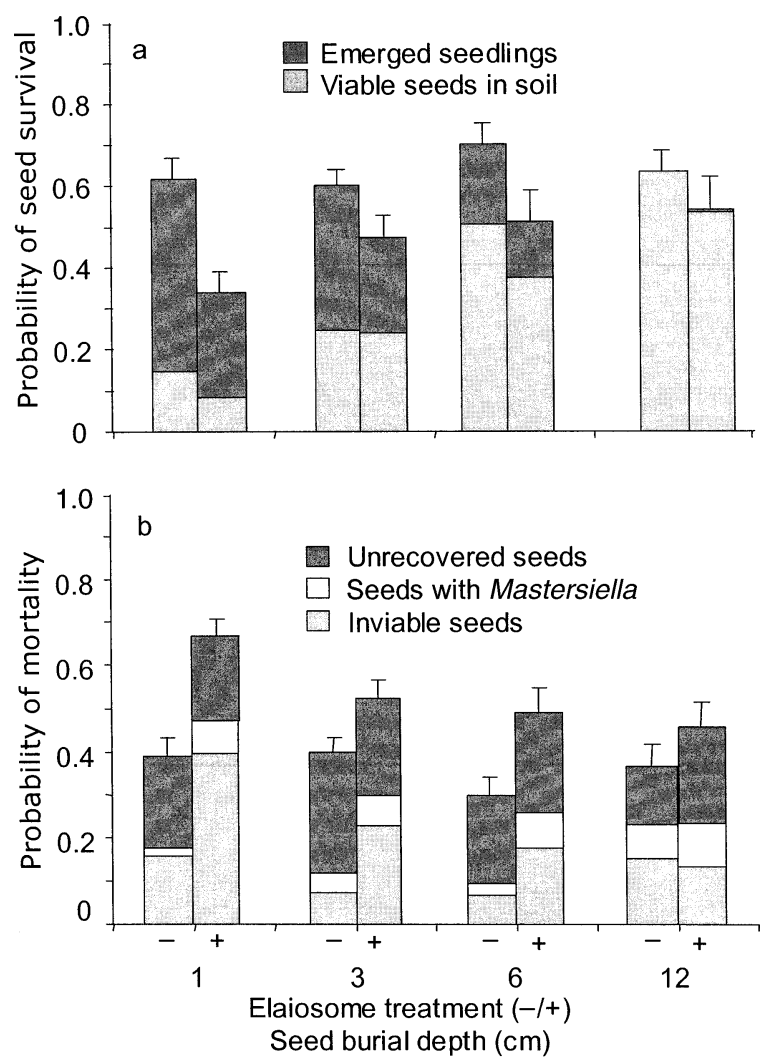

FIG. 3. Probability (means $+1 \mathrm{SE}$ ) of (a) survival and (b) mortality for seeds of Leucospermum truncatulum seeds with and without elaisomes at four burial depths.

elaiosome removal, indicating that the negative impact of elaiosomes on survival is consistent across all seed burial depths (Table 1a).

Elaiosomes and burial depth affected two of the three seed mortality factors measured. First, elaiosomes reduced the viability of seeds that remained in the soil by an average of $68 \%\left(F_{1,62}=16.54, P=0.0001\right.$; Fig. $3 \mathrm{~b})$. Seed viability also increased with greater burial depth $\left(F_{3,62}=6.83, P=0.0005\right)$, but there was no significant elaiosome $\times$ depth interaction $\left(F_{3,62}=1.72\right.$, $P=0.171)$. Second, attack by Mastersiella roots was nearly twice as high for seeds with elaiosomes relative to those without, but this difference was only marginally significant $\left(F_{1,62}=2.91, P=0.093\right.$; Fig. 3b). Depth did not significantly influence mortality due to Mastersiella $\left(F_{3,62}=1.11, P=0.3540\right)$. Finally, neither elaiosomes nor burial depth had a significant effect on the proportion of seeds unrecovered from baskets (elaiosomes, $F_{1,62}=0.457, P=0.501$; depth, $F_{3,62}=$ $1.50, P=0.224)$, suggesting that attrition from seed banks due to seed predation or other factors was consistent across all treatment levels (Fig. 3b).

For viable seeds escaping mortality by Mastersiella and seed predators, greater burial depths significantly reduced the probability of emergence as a seedling (Table 1b, Fig. 4). Accordingly, burial depth had an equal but opposite effect on seed persistence within the soil, which was greatest for seeds buried at $12 \mathrm{~cm}$. Elaiosomes did not influence the conditional emergence probability (Table $1 \mathrm{~b}$ ), and the block and elaiosome $\times$ depth interaction terms were not significant (Table 1b).

Seed burial depth and the presence of elaiosomes had no significant effects on the survival of emerged seedlings during the first year after the prescribed fire (Table 1c). Although overall seedling mortality was not significantly affected by the experimental treatments, the causes of mortality varied with emergence depth. Seedlings from shallowly planted seeds were predominantly attacked by baboons (51\% of all seedling mortality in first census period), whereas seedlings from deeper planted seeds died due to herbivory (weevils, polyphagous caterpillars, and grysbok) and other causes (wilting and rotting).

Seedling performance.-Although there was no effect of burial depth on seedling survival through the first year, depth significantly influenced seedling performance measures, as indicated by a significant main effect of depth in the MANOVA $\left(F_{6,88}=2.43, P=\right.$ 0.032 , Roy's greatest root $=0.248$ ). Subsequent protected ANOVAs demonstrated that seeds buried deeply emerged later in the season $\left(F_{2,36}=5.10, P=0.011\right)$, and had smaller cotyledons relative to seeds at shallower depths $\left(F_{2,45}=5.25, P=0.010\right)$. Elaiosomes and the elaiosome $\times$ depth interaction did not significantly affect any of the seedling performance measures (all $P$ values $>0.09$ ).

Net effects.-Overall, total survival [(number of dormant seeds + number of seedlings $) \div$ initial number of seeds/basket] during the first year after the burn increased with burial depth, with maximum survival found at burial depths of $6 \mathrm{~cm}$ and $12 \mathrm{~cm}\left(F_{3,42}=12.58\right.$, $P<0.0001$; Fig. 5c). The net effect of deeper burial was due to higher survival of seeds persisting in the soil (Fig. 5a), despite lower survival of seedlings (Fig. $5 \mathrm{~b})$. At a depth of $6 \mathrm{~cm}, 77 \%$ of the surviving population was comprised of persistent seeds stored in the soil, demonstrating that substantial seed dormancy occurs during the first year after a fire. Our experiment

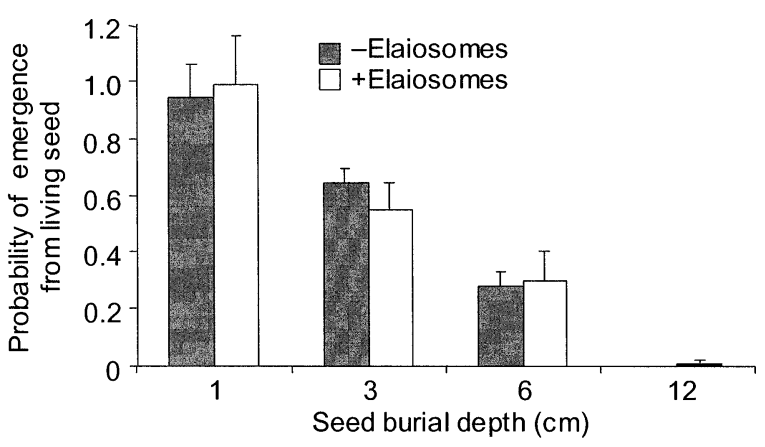

FIG. 4. Probability (means $+1 \mathrm{SE}$ ) of seedling emergence from seeds of Leucospermum truncatulum with and without elaiosomes at four burial depths. 

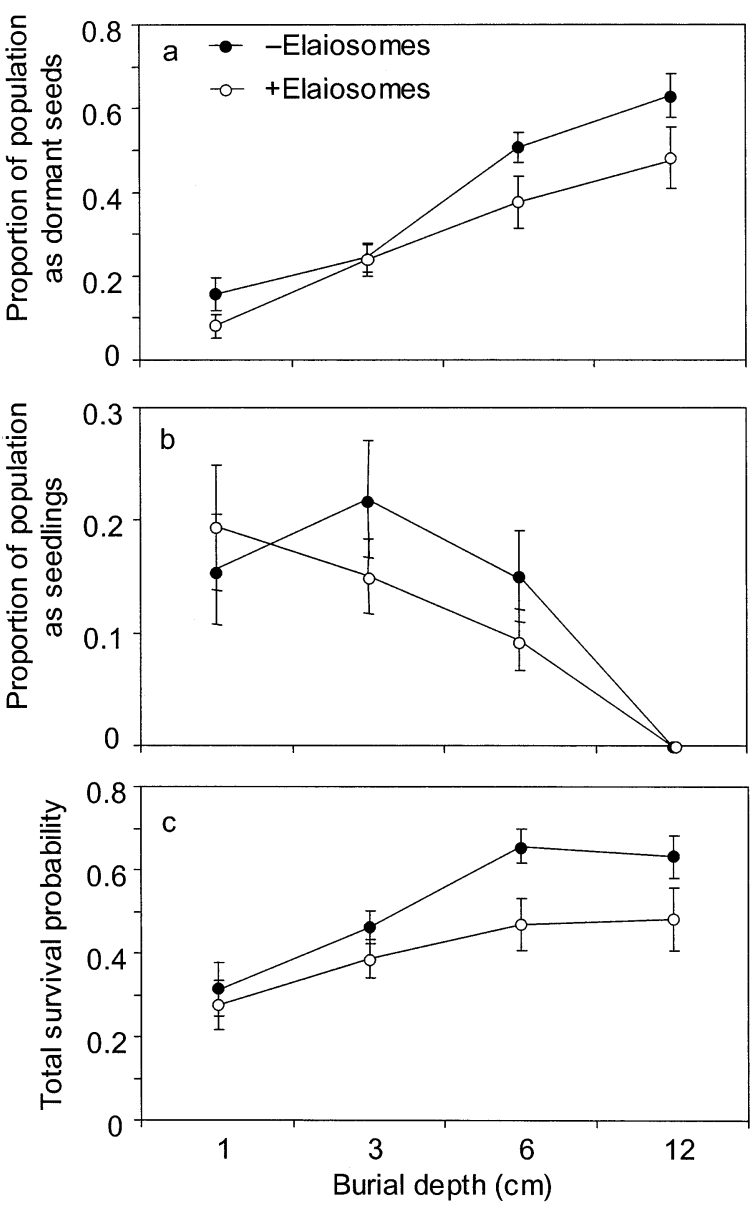

FIG. 5. The net effects (means $\pm 1 \mathrm{SE}$ ) of elaiosomes and seed burial depth on (a) the proportion of seeds that remained viable and dormant for one year (number of viable, ungerminated seeds $\div$ initial number of seeds), (b) the proportion of seeds that emerged as seedlings and survived for one year (number of seedlings surviving one year $\div$ initial number of seeds), and (c) the total probability of an individual surviving as a seed or as a seedling for one year [ number of viable seeds + number of seedlings $) \div$ initial number of seeds $]$.

also demonstrated that total survival was greater for seeds without elaiosomes $\left(F_{1,62}=6.52, P=0.013\right)$. This difference was due to the fact that elaiosomes reduce the probability of a seed persisting, rather than affecting the probability of a seed successfully recruiting as a seedling.

\section{DISCUSSION}

In this paper, we used field experiments to demonstrate that two components of seed dispersal by ants (elaiosome removal and seed burial) give rise to tradeoffs that occur during seldom-measured stages of early recruitment. The removal of elaiosomes had a strong positive effect on the survival of buried seeds of a South African shrub (Leucospermum truncatulum), especially in the presence of vertebrate predators. However, in contrast with other studies (e.g., Lobstein and
Rockwood 1993, Horvitz and Schemske 1994), we found that elaiosomes had no effect on seedling emergence rates. Deeper seed burial also enhanced seed survival, yet imposed potential demographic costs by delaying and inhibiting seedling emergence. Such shifts in the costs and benefits of dispersal across different life cycle stages suggest a conflict between plant dispersal requirements (e.g., predator avoidance) and recruitment requirements (e.g., favorable environment for germination, emergence, and growth).

After seeds are buried, elaiosomes continue to influence their survival by attracting a variety of natural enemies. In the seed-predator exclusion experiment, Leucospermum seeds with elaiosomes suffered higher mortality in the presence of vertebrates, relative to seeds without elaiosomes (Fig. 2). Whether predation will be a major source of mortality for buried seeds in natural populations will depend on the rate at which ants remove elaiosomes once the seeds are buried and the extent to which ants deter rodent predators. Previous studies have also shown that rodents can more readily discover buried seeds with elaiosomes (Heithaus 1981), but their ability to detect seeds diminishes with burial depth (Bond and Breytenbach 1985). Although we also found a significant effect of burial depth on seed survival (Table 1a), there was no interaction between depth and the presence of elaiosomes, suggesting that increased mortality near the soil surface could not be explained by rodent granivory alone. Greater mortality at the $1-\mathrm{cm}$ depth may also be explained by higher soil temperatures typically found near the surface during fire.

In both of our experiments, viability was significantly reduced for seeds with elaiosomes compared to seeds without elaiosomes (Fig. 3b). Two factors may explain this result. First, because elaiosomes persist for at least one year, the fleshy tissue of this structure may facilitate attack of seeds by soil pathogens and microbes that promote seed decay. Second, we found that seeds with elaiosomes were nearly twice as likely to be covered with the attached roots of a hemi-parasitic plant, Mastersiella digitata, relative to bare seeds (Fig. $3 b)$. Thus, although elaiosomes initially enhance seed survival by promoting the chances of seed dispersal by ants, these structures appear to impose costs by attracting a range of natural enemies. Seeds with this adaptation to dispersal by ants will be particularly vulnerable when mutualist dispersers are rare or absent.

Seedling recruitment is conditional on both seed survival and germination, but the consequences of dispersal for these demographic stages are only partially observable. Failed germination events are typically not seen, while seed mortality is often unmeasured (Rees and Long 1993). For these reasons, germination rates are typically inferred from observed recruitment patterns. Using this approach, previous studies have concluded that the removal of elaiosomes enhances germination rates, demonstrating a further benefit of dis- 
persal (Horvitz 1981, Lobstein and Rockwood 1993). Although our data also indicated a net positive effect of elaiosome removal on seedling recruitment, this result was due almost entirely to enhanced seed survival (Fig. 3a, Table 1a), rather than increased seed germination, seedling emergence, or seedling survival (Fig. 4, Table 1b; also see Slingsby and Bond 1985). Distinguishing the effects of elaiosome removal on seed mortality from those on seedling emergence is essential for determining the underlying mechanisms shaping final recruitment patterns. For example, by enhancing survival of dormant seeds in the soil, elaiosome removal should improve the population's ability to recruit after fire.

Although elaiosomes did not significantly affect any stages beyond seed survival during the first year, seed burial depth had consequences at multiple steps during early recruitment (Table 1). In particular, seeds buried deeply had a greater chance of surviving, relative to seeds located near the soil surface (Table 1a, Fig. 3), presumably due to a combination of lower predation rates and protection from fire. Despite enhanced survival at greater depths, deeper burial also increased seed dormancy, a potentially negative effect documented in greenhouse experiments done in other systems (Auld 1986, Bond et al. 1999).

Seed dormancy could be costly if individuals die before they are able to germinate (and ultimately attempt reproduction), or if competition among lineages favors those with the shortest germination time and fastest potential intrinsic rate of increase (Stearns 1976). The cost of enhanced dormancy will depend largely on two components of the environment known to fluctuate widely in fire-dependent fynbos communities. The extent to which greater dormancy is a cost will depend on the timing of the next recruitment opportunity (e.g., fire) relative to seed mortality rates: If a large fraction of seeds die in the soil between relatively infrequent recruitment events, deeper burial by ants would impose a significant fitness cost. Studies on related species suggest that seeds from other species of large-seeded Proteaceae can survive at least 15 years after adult populations senesce (Rourke 1976). A second variable component affecting recruitment is fire intensity. Many previous studies have demonstrated that a seed's ability to emerge from greater soil depths or its vulnerability to excessive temperatures depend on fire intensity (Auld 1986, Brits 1987, Bond et al. 1999). Thus, high-intensity fires may ameliorate costs associated with deep burial (Bond et al. 1990).

Despite the potential demographic costs of deeper seed burial, increased seed persistence associated with burial may provide a benefit to a lineage by buffering it from complete extinction in a variable environment (Cohen 1966, Templeton and Levin 1979). Although complete emergence would maximize the lineage's potential rate of increase, genotypes without dormant seeds would become extinct the first time reproduction failed completely (Venable and Brown 1988). Such events occur commonly in fynbos, where fire often kills aboveground plants before they reach reproductive maturity. During long fire-free intervals, dormant seeds may be the only life cycle stage represented in populations after adult plants senesce and die. Given the extreme variability in fire frequency in fynbos, the net effects of seed burial by ants on plant populations will depend on how temporal variability in fire regimes influences cost-benefit thresholds associated with dormancy and seed mortality.

In addition to reducing the probability of emergence after fire, deeper burial may pose a number of challenges during early seedling establishment. First, deeper burial was associated with later emergence in the season. In competitive environments, early emergence may result in a priority effect whereby the first seedlings that establish have greater access to resources and have a higher chance of surviving (Stanton 1985, Kalisz 1986, Dyer et al. 2000). In our study, although seedlings took longer to emerge from deeply buried seeds, burial depth did not affect seedling height or survival through the first year. One explanation for this result is that early emergence also imposed costs for seedlings: those that emerged earlier in the season were more "apparent" to natural enemies in the postfire landscape, especially baboons. Consequently, seedlings emerging from $1 \mathrm{~cm}$ deep were most susceptible to higher predation and herbivory levels that we observed earlier in the season. Over $25 \%$ of the seedlings emerging early from $1 \mathrm{~cm}$ depth were attacked by baboons. Due to later emergence associated with deeper burial, only $8 \%$ of the seedlings from $3 \mathrm{~cm}$ deep died due to baboon predation, and no seedlings emerging from $6 \mathrm{~cm}$ or deeper were killed by baboons. Similarly, herbivory by polyphagous caterpillars and weevils was greatest during the early part of the season. Thus, although early emergence may enhance seedling growth, it may come at the expense of greater exposure to herbivores.

A second way in which deeper seed burial may be costly to seedlings is by reducing the size of cotyledons. Because cotyledons provide the only nutrition to seedlings during the early phases of recruitment, a reduction in their size could greatly influence later seedling performance (Harper 1977). In both natural and experimental populations, we found that Leucospermum seedlings emerging from greater depths had significantly smaller cotyledons relative to those emerging from shallower depths, suggesting that deeper emergence may require more of a seed's reserves. Despite this finding, the negative effects of smaller cotyledons did not persist through later recruitment stages to affect seedling growth and survival during the first year. The effects of other factors, such as biotic interactions and abiotic conditions, may have obscured any negative consequences of smaller cotyledons. 
Whether seed burial by ants imposes a net cost or benefit may also depend on the ant species dispersing seeds. For naturally occurring Leucospermum, the depth from which seedlings emerge has a bimodal distribution (Fig. 1). Although this pattern may be due to chance alone, a more likely explanation is varying dispersal behavior among common dispersers of Leucospermum. Anoplolepis species, the dominant dispersers, store seeds in underground networks of storage chambers (mean depth of $5 \mathrm{~cm}$ ) and deep nest chambers (mean depth of $45 \mathrm{~cm}$ ) (Steyn 1954). Other dispersers, such as Pheidole capensis and Tetramorium quadrispinosum, are more opportunistic in their nesting behavior, and are often found in shallow nests at the base of vegetation (e.g., restio tussocks) or under rocks (C. E. Christian, personal observation). We hypothesize that seeds dispersed by species such as Pheidole and Tetramorium will emerge more rapidly after fire, whereas deeper burial by Anoplolepis may result in greater dormancy, increasing seed reserves in the population.

\section{Conclusion}

Determining the net fitness effects of dispersal is especially important in South African fynbos, where the invasive Argentine ant (Linepithema humile) is eliminating many of the native seed-dispersing ant species, especially Anoplolepis and Pheidole. Because the Argentine ant does not disperse and bury seeds, predation levels are dramatically higher in invaded areas (Bond and Slingsby 1984, Christian 2001). Although some native seed dispersers can coexist with Argentine ants, they are not as efficient at dispersing the large seeds of Leucospermum and presumably do not bury seeds as deeply as Anoplolepis due to their shallow nest structure. Based on our findings, an overall decrease in seed burial depth would lead to lower seed survival, as well as increased seedling emergence, and thus a reduction in the fraction of seeds that persist as dormant seeds. Because dormant seeds may play a crucial role in buffering populations from variable fire regimes, populations in invaded areas may experience higher risks of extinction due to reduced population size and buffering capacity.

\section{ACKNOWLEDGMENTS}

We thank Hall Cushman, Dan Doak, and Marcel Rejmanek for their insightful comments on this paper. Comments from Naomi Cappuccino, Johannes Kollmann, and an anonymous reviewer greatly improved the clarity of this paper. Eric Baack, Denise Theide, Phil Ward, and Kevin Rice also contributed thoughtful suggestions at various stages during this project. We are also indebted to Eric Baack, Brian Barringer, Hall Cushman, Amida Johns, Anton Pauw, Tilla Raimondo, and Darelle Snyman for their assistance in the field. We are especially grateful of Cape Nature Conservation for allowing us to conduct this work in the Kogelberg Biosphere Reserve and for conducting several prescribed burns in support of this research. We also extend special thanks to Mark and Amida Johns, Anton Pauw, Hamish Robertson, and William Bond for their advice, logistical support, and friendship throughout the project. We also thank Schalk Louw for the weevil identifications. This work was supported by NSF grant INT-98194 (CEC), the Center for Population Biology at UC Davis, and the Achievements Rewards for College Scientists Foundation.

\section{Literature Cited}

Addicott, J. F. 1986. On the population consequences of mutualism. Pages 425-436 in J. Diamond and T. J. Case, editors. Community ecology. Harper and Row, New York, New York, USA.

Anderson, A. N. 1988. Dispersal distance as a benefit of myrmechochory. Oecologia 75:507-511.

Augspurger, C. K. 1983. Offspring recruitment around tropical trees: changes in cohort distance with time. Oikos 40: 189-196.

Auld, T. D. 1986. Population dynamics of the shrub Acacia suaveolens ( $\mathrm{Sm}$.) Willd.: dispersal and the dynamics of the soil seed-bank. Australian Journal of Ecology 11:235-254.

Black, J. N. 1956. The influence of seed size and depth of sowing on pre-emergence and early vegetative growth of subterranean clover (Trifolium subterraneum L.). Australian Journal of Agricultural Research 7:98-109.

Bond, W. J., and G. J. Breytenbach. 1985. Ants, rodents and seed predation in Proteaceae. South African Journal of Zoology 20:150-154.

Bond, W. J., M. Honig, and K. E. Maze. 1999. Seed size and seedling emergence: an allometric relationship and some ecological implications. Oecologia 120:132-136.

Bond, W. J., D. Le Roux, and R. Erntzen. 1990. Fire intensity and regeneration of myrmecochorous Proteaceae. South African Journal of Botany 56:326-330.

Bond, W. J., and P. Slingsby. 1984. Collapse of an ant-plant mutualism: the Argentine ant (Iridomyrmex humilis) and myrmecochorous Proteaceae. Ecology 65:1031-1037.

Bond, W. J., and W. D. Stock. 1989. The costs of leaving home: ants disperse myrmecochorous seeds to low nutrient sites. Oecologia 81:412-417.

Boucher, C. 1978. Cape Hangklip area. II. The vegetation. Bothalia 12:455-497.

Brits, G. J. 1987. Germination depth vs. temperature requirements in naturally dispersed seeds of Leucospermum cordifolium and L. cuneiforme (Proteaceae). South African Journal of Botany 53:119-125.

Bronstein, J. L. 1994. Conditional outcomes in mutualistic interactions. Trends in Ecology and Evolution 9:214-217.

Carney, S. E., M. B. Byerley, and D. A. Holway. 2003. Invasive Argentine ants (Linepithema humile) do not replace native ants as seed dispersers of Dendromecon rigida $(\mathrm{Pa}-$ paveraceae) in California, USA. Oecologia 135:576-582.

Christian, C. E. 2001. Consequences of biological invasion reveal importance of mutualism for plant communities. $\mathrm{Na}-$ ture 413:635-639.

Christian, C. E. 2002. Dynamics of a seed dispersal mutualism: costs, benefits, and the consequences of a biological invasion. Dissertation. University of California, Davis, California, USA.

Cohen, J. 1966. Optimizing reproduction in a randomly varying environment. Journal of Theoretical Biology 12:119129.

Cowling, R. M. 1992. The ecology of fynbos: nutrients, fire and diversity. Oxford University Press, Cape Town, South Africa.

Cushman, J. H., and T. W. Whitham. 1989. Conditional mutualism in a membracid-ant association: temporal, age-specific, and density-dependent effects. Ecology 70:10401047.

Dyer, A. R., A. Fenech, and K. J. Rice. 2000. Accelerated seedling emergence in interspecific competitive neighborhoods. Ecology Letters 3:523-529. 
Feldman, R., D. F. Tomback, and J. Koehler. 1999. Cost of mutualism: competition, tree morphology, and pollen production in limber pine clusters. Ecology 80:324-329.

Fuchs, M. A., P. G. Krannitz, and A. S. Harestad. 2000. Factors affecting emergence and first-year survival of seedlings of Garry oaks (Quercus garryana) in British Columbia, Canada. Forest Ecology and Management 137:209-219.

Guo, K., L. Rui, and M. J. A. Werger. 2001. Effect of acorn burying depth on germination, seedling emergence and development of Quercus aliena var. acuteserrata. Acta Botanica Sinica 43:974-978.

Hanzawa, F. M., A. J. Beattie, and D. C. Culver. 1988. Directed dispersal: demographic analysis of an ant-seed mutualism. American Naturalist 131:1-13.

Harper, J. L. 1977. Population biology of plants. Academic Press, London, UK.

Heithaus, E. R. 1981. Seed predation by rodents on three ant-dispersed plants. Ecology 62:136-145.

Holway, D. A., L. Lach, A. V. Suarez, N. D. Tsutsui, and T. J. Case. 2002. Causes and consequences of ant invasions. Annual Review of Ecology and Systematics 33:181-283.

Horvitz, C. C. 1981. Analysis of how ant behaviors affect germination in a tropical myrmecochore Calathea microcephala (P. \& E) Koernicke (Marantaceae): microsite selection and aril removal by neotropical ants, Odontomachus, Pachycondyla, and Solenopsis (Formicidae) in Veracruz, Mexico. Oecologia 51:47-52.

Horvitz, C. C., and D. W. Schemske. 1990. Spatiotemporal variation in insect mutualists of a neotropical herb. Ecology 71:1085-1097.

Horvitz, C. C., and D. W. Schemske. 1994. Effects of dispersers, gaps, and predators on dormancy and seedling emergence in a tropical herb. Ecology 75:1949-1958.

Horvitz, C. C., and D. W. Schemske. 1995. Spatiotemporal variation in demographic transitions of a tropical understory herb: projection matrix analysis. Ecological Monographs 65:155-192.

Howe, H. F. 1990. Seed dispersal by birds and mammals: implications for seedling demography. Pages 191-218 in K. S. Bawa and M. Hadley, editors. Reproductive ecology of tropical forest plants. Man and biosphere series number 7. UNESCO and Parthenon Publishing Group, Paris, France.

Hughes, L., and M. Westoby. 1992. Effect of diaspore characteristics on removal of seeds adapted for dispersal by ants. Ecology 73:1300-1312.

Janzen, D. H. 1970. Herbivores and the number of tree species in tropical forests. American Naturalist 104:501-528.

Jordano, P., and C. M. Herrera. 1995. Shuffling the offspring: uncoupling and spatial discordance of multiple stages in vertebrate seed dispersal. Ecoscience 2:230-237.

Kalisz, S. 1986. Variable selection on the timing of germination in Collinsia verna (Scrophulariaceae). Evolution 40: 479-491.

Kalisz, S. 1991. Experimental determination of seed bank age structure in the winter annual Collinsia verna. Ecology 72:575-585.

Kalisz, S., F. M. Hanzawa, S. J. Tonsor, D. A. Thiede, and S. Voigt. 1999. Ant-mediated seed dispersal affects dis- tance, density and spatial pattern of seed relatedness in Trillium grandifolium. Ecology 80:2620-2634.

Lobstein, M. B., and L. L. Rockwood. 1993. Influence of elaiosome removal on germination in five ant-dispersed plant species. Virginia Journal of Science 44:59-72.

Midgley, J., B. Anderson, A. Bok, and T. Fleming. 2002. Scatter-hoarding of Cape Proteaceae nuts by rodents. Evolutionary and Ecological Research 4:623-626.

Musil, C. F. 1991. Sand bank dynamics in sand plain lowland fynbos. South African Journal of Botany 57:131-142.

Pierce, S. M., and R. M. Cowling. 1991. Dynamics of soilstored seed banks of six shrubs in fire-prone dune fynbos. Journal of Ecology 79:731-747.

Pudlo, R. J., A. J. Beattie, and D. C. Cutler. 1980. Population consequences of changes in an ant-seed mutualism in Sanguinaria canadesis. Oecologia 146:32-37.

Rees, M., and M. J. Long. 1993. The analysis and interpretation of seedling recruitment curves. American Naturalist 141:233-262.

Reichman, O. J. 1980. Desert granivore foraging and its impact on seed densities and distributions. Ecology 60:10851092.

Rourke, J. P. 1976. Beyond redemption: the story of Mimetes stokoei. Veld and Flora 62:12-16.

SAS Institute. 1998. SAS system for Windows. Version 8.0. Cary, North Carolina, USA.

Schupp, E. W. 1995. Seed-seedling conflicts, habitat choice, and patterns of plant recruitment. American Journal of Botany 82:399-409.

Seiwa, K., A. Watanabe, T. Saitoh, H. Kannu, and S. Akasaka. 2002. Effects of burying depth and seed size on seedling establishment of Japanese chesnuts, Castanea crenata. Forest Ecology and Management 164:149-156.

Slingsby, P., and W. J. Bond. 1985. The influence of ants on the dispersal distance and seedling recruitment of Leucospermum conocarpodendron (L.) Buek (Proteaceae). South African Journal of Botany 51:30-34.

Stanton, M. L. 1985. Seed size and emergence time within a stand of wild radish (Raphanus raphinistum L.): the establishment of a fitness hierarchy. Oecologia 67:524-531.

Stearns, S. C. 1976. Life history tactics: a review of ideas. Quarterly Review of Biology 51:3-47.

Steyn, J. J. 1954. The pugnacious ant (Anoplolepis custodiens Smith) and its relation to the control of citrus scales at Letaba. Entomological Society of Southern Africa, Pretoria, South Africa.

Templeton, A. R., and D. A. Levin. 1979. Evolutionary consequences of seed pools. American Naturalist 11:232-249.

Van der Pijl, L. 1972. Principles of dispersal in higher plants. Springer-Verlag, Berlin, Germany.

Venable, D. L., and J. S. Brown. 1988. The selective interactions of dispersal, dormancy, and seed size as adaptations for reducing risk in variable environments. American Naturalist 1:320-384.

Wesson, G., and P. F. Wareing. 1967. Light requirements of buried seeds. Nature 213:600-601.

Zar, J. H. 1996. Biostatistical analysis. Prentice-Hall, Upper Saddle River, New Jersey, USA.

Zettler, J. A., T. P. Spira, and C. R. Allen. 2001. Ant-seed mutualisms: can red imported fire ants sour the relationship? Biological Conservation 101:249-253. 